\title{
Cyclic extrusion compression angular pressing (CECAP) as a novel severe plastic deformation method for producing bulk ultrafine grained metals
}

\author{
Mahnaz Ensafi, Ghader Faraji*, Hooman Abdolvand \\ School of Mechanical Engineering, College of Engineering, University of Tehran, Tehran 11155-4563, Iran. \\ *Corresponding author, email: ghfaraji@ut.ac.ir; Tel. / Fax: +982161119966.
}

\begin{abstract}
In the current study, a novel severe plastic deformation (SPD) technique entitled cyclic extrusion channel angular pressing (CECAP) is proposed appropriate for producing ultrafine grained cylindrical material. In this new method, cyclic extrusion compression (CEC) and equal channel angular pressing (ECAP) processes are combined which solves drawbacks of both processes. Advantageous of the new process may be considered in two views of points of processing and properties. This new process increases the hydrostatic compressive stress of ECAP as well as shear to the total strain of CEC. Also, CECAP solves needing back pressure problem of CEC process which is an important feature of the new process. The process treated an AZ91 alloy and remarkable grain refinement and significant improvement in strength, ductility and hardness were achieved because of higher hydrostatic compressive stresses.
\end{abstract}

Keywords: CECAP; Nanocrystalline materials; AZ91 alloy; hydrostatic compressive stress; Metals and alloys.

\section{Introduction}

Severe plastic deformation (SPD) as robust techniques for producing ultrafine grained (UFG) metals with enhanced mechanical properties have received much attention in recent years [1,2]. In all SPD methods, a significant amount of plastic strain is applied without any change in final geometrical dimension of the workpiece leading to UFG structure [3, 4]. Some of the SPD processes for bulk metals are equal channel angular pressing (ECAP) [5, 6] and cyclic extrusion compression (CEC) [7]. Several works have been performed in recent years to increase the efficiency of the ECAP process by modifying conventional ECAP such as twist channel angular pressing (TCAP) [8], and ECAPConform [9]. The major disadvantage of CEC method which needs back pressure during the process can be obtained by utilizing dual press and complex equipment. So, this limitation leads to increase the processing cost and time. Back pressure which is provided by a second punch is so essential in CEC process. It provides required pressure to expand the material and increase its diameter to the initial value. To solve this problem, cyclic expansion extrusion (CEE) as a modification of CEC was 
introduced to eliminate this limitation by Pardis et al. [10]. However, back pressure is needed at the first step of CEE, and also the hydrostatic compressive stress in CEE is less than CEC process. As is known, hydrostatic compressive stress is the main feature of SPD processing to achieve UFG metals with excellent mechanical properties [11]. Also, the drawback of ECAP process which is a lack of hydrostatic pressure during the process is compensated.

The aim of the current study is to introduce a new technique which can resolve the limitation of CEC and ECAP processes while improving their efficiency. Novel proposed method was entitled CECAP which consists of two subsequently CEC and ECAP processes. To investigate the applicability of this new method, an AZ91 alloy was treated, and microstructure and mechanical properties were studied.

\section{Principles of the CECAP process}

CECAP process is shown schematically in Fig. 1. The bulk cylindrical sample is put into the die input channel. Deformation zone in this process consists of two parts. At the first part, the initial cylindrical metal is extruded to reduce its diameter (Fig. 1(c)). The reduced diameter reaches the channel end and compressed. Then, the material is pressed into the angular channel to be laterally extruded (Fig. 1(e)). The angular part of the CECAP die provides the required back pressure to compressed the sample to increase its diameter to original diameter. So, CEC process is performed without using the dual press to provide the necessary backpressure for compression stage. Also, it causes to accumulate more plastic strain into the sample compared to simple CEC method.

The equivalent plastic strain in ECAP [12] and CEC processes [13] can be estimated via Eq. (1) and Eq. (2), respectively.

$$
\begin{aligned}
& \varepsilon=\frac{1}{\sqrt{3}}\left\{2 \cot \left(\frac{\varphi}{2}+\frac{\psi}{2}\right)+\psi \operatorname{cosec}\left(\frac{\varphi}{2}+\frac{\psi}{2}\right)\right\} \\
& \varepsilon=4 \ln \frac{D}{d}
\end{aligned}
$$

Where $\varphi, \psi, D$ and $d$ are shown in Fig. 1(a). Therefore, equivalent strain after $\mathrm{N}$ passes of CECAP can be achieved by Eq. (3) which is a sum of the Eq. (1) and Eq. (2).

$$
\varepsilon_{\text {tot }}=N\left(\frac{1}{\sqrt{3}}\left\{2 \cot \left(\frac{\varphi}{2}+\frac{\psi}{2}\right)+\psi \operatorname{cosec}\left(\frac{\varphi}{2}+\frac{\psi}{2}\right)\right\}+4 \ln \frac{D}{d}\right)
$$

The total equivalent strain at each pass of CECAP, considering die parameters in the current study is calculated from the Eq. (3) which is about 1.64. 
(a)

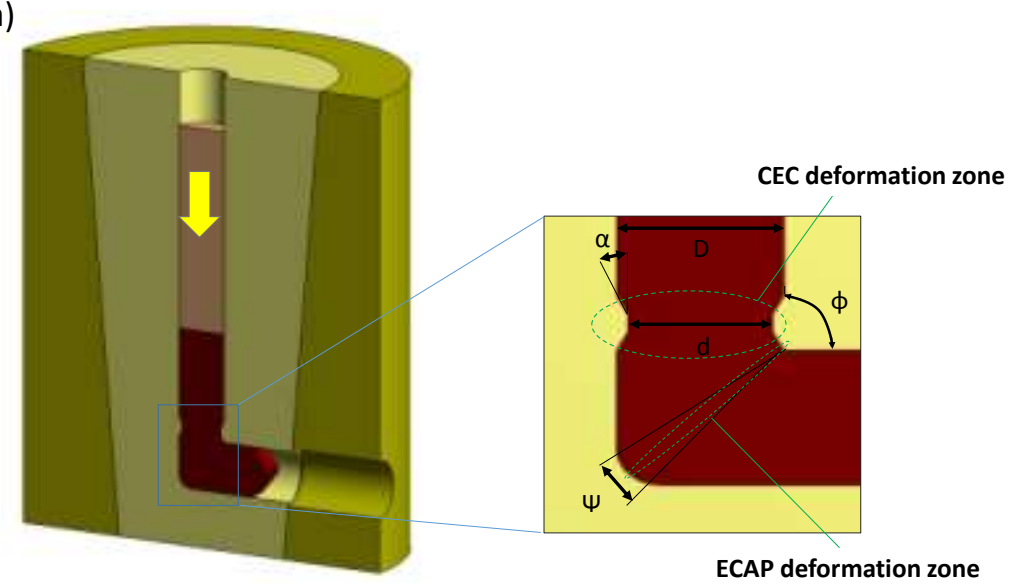

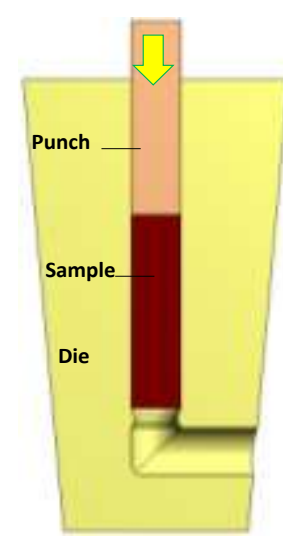

(b)

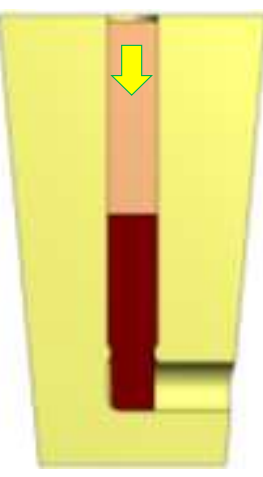

(c)

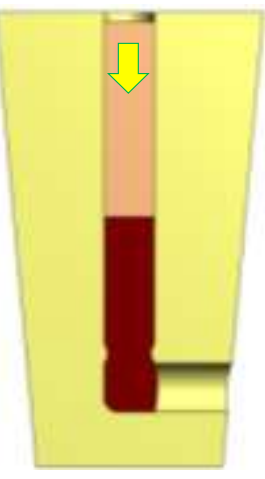

(d)

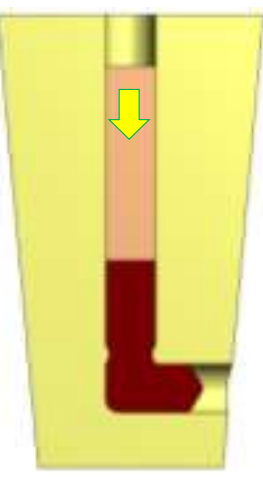

(e)

Fig. 1. (a) Schematic of the CECAP process and die parameters, and (b)-(e) different stages of the process.

\section{Experimental and FEM procedures}

An as-cast AZ91 magnesium alloy was used for the experiments. The initial sample was machined to a diameter of $15 \mathrm{~mm}$ and a length of $100 \mathrm{~mm}$ from the ingot. Die parameters of CECAP process (Fig. 1(a)), are as following: the channel angles $\varphi=90^{\circ}$, the angle of the curvature $\psi=10^{\circ}$, $\alpha=30^{\circ}, d=13 \mathrm{~mm}$, and $D=15 \mathrm{~mm}$. One cycle of the CECAP process (effective strain of about 1.64) was conducted at a constant temperature of $300{ }^{\circ} \mathrm{C}$ at a ram speed of $10 \mathrm{~mm} / \mathrm{min}$. Because of the poor ductility of magnesium alloys at room temperature, the process was performed at $300^{\circ} \mathrm{C}$. The die and sample was heated by an electric heater so that temperature of the sample be kept constant at $300{ }^{\circ} \mathrm{C}$. The sample and die were sprayed by molybdenum disulfide $\left(\mathrm{MoS}_{2}\right)$ as a lubricant. In order to avoid static recrystalization, the processed sample was rapidly cooled upto room temperature in air. The tensile test sample from the processed specimen was cut along the extrusion direction in which the metal experiences both CEC and ECAP processes. The tensile tests were carried out at room temperature at an initial strain rate $10^{-3} \mathrm{~s}^{-1}$. To investigate the microstructure, samples were prepared by the standard metallographic techniques and analyzed by optical microscopy. An image analysis 
sofware ,named J-micro vision, was used to measure the grain size. The Vickers microhardness testing was performed with a load of $100 \mathrm{gr}$ for $10 \mathrm{sec}$. Finite element simulations were carried out using commercial software DEFORM-3D to investigate the hydrostatic pressure during the processes.

\section{Result and discussion}

Fig. 2a and $2 b$ show the picture of CECAP processed sample and an optical micrograph of the unprocessed structure, respectively. As shown, initial microstructure contains coarse grains with a mean grain size of $\sim 200 \mu \mathrm{m}$ and a dendritic structure of $\alpha-\mathrm{Mg}$ phase surrounded by networks of $\beta$ phase $\left(\mathrm{Mg}_{17} \mathrm{Al}_{12}\right)$ at grain boundaries which indicated by arrows. After one pass CECAP process, average grain size was significantly reduced to $\sim 3 \mu \mathrm{m}$. Different regions of the cross-section A-A (Fig. 2a) of the processed sample are selected. As it can be seen in Fig. 2(b), grain refinement in outer regions which are near to the surface is more intensive which are thoroughly consistent with higher imposed strain. During hot deformation, usually dynamic recrystallization (DRX) occures and a lot of factors can influence on it [14]. As indicated, afte process ultrafine grains achieved because of DRX. Severe plastic strain replaced fine and recrystallized grains with broken $\beta$ phase networks. Both grain refinement and $\beta$ phase dissolution and refinement severely influence on mechanical property [15-17]. As it can be seen, most of the fine grains were formed at adjacency of the $\beta$ particles because of impeding dislocation movement which leads to accumulation of dislocation. As a result, it caused nucleation of new finer grains $[18,19]$. Breaking of these hard networks and refining grain size lead to improving both strength and ductility [20]. Grain refinement did not occur considerably in region B which is the center of the sample, and some unrecrystallized regions still exist.

Fig. 3a shows the tensile true stress-true strain curves of the unprocessed and CECAP processed samples. As depicted, the as-received specimen has low ductility because of the limited slip systems at room temperature and dendritic structure of $\beta$ phase along grain boundaries. These are responsible for poor mechanical properties of the as-cast AZ91 sample [21]. As shown, a remarkable improvement in strength achieved after CECAP process. It was increased to $234 \mathrm{MPa}$ from an initial value of $144 \mathrm{MPa}$ (about 63\%). Severe reduction and homogeneous distribution of the grains lead to significant increase of the strength [20]. A significant increase in the strength can be attributed to a considerable grain refinement and dissolution of $\beta$ phase achieved after CECAP process. Also, the ductility was significantly increased from $4 \%$ for the unprocessed sample to $8 \%$ for processed sample. Applying an intense strain in this novel approach leads to a homogeneously distribution and precipitation of $\beta$ phase in the microstructure. 

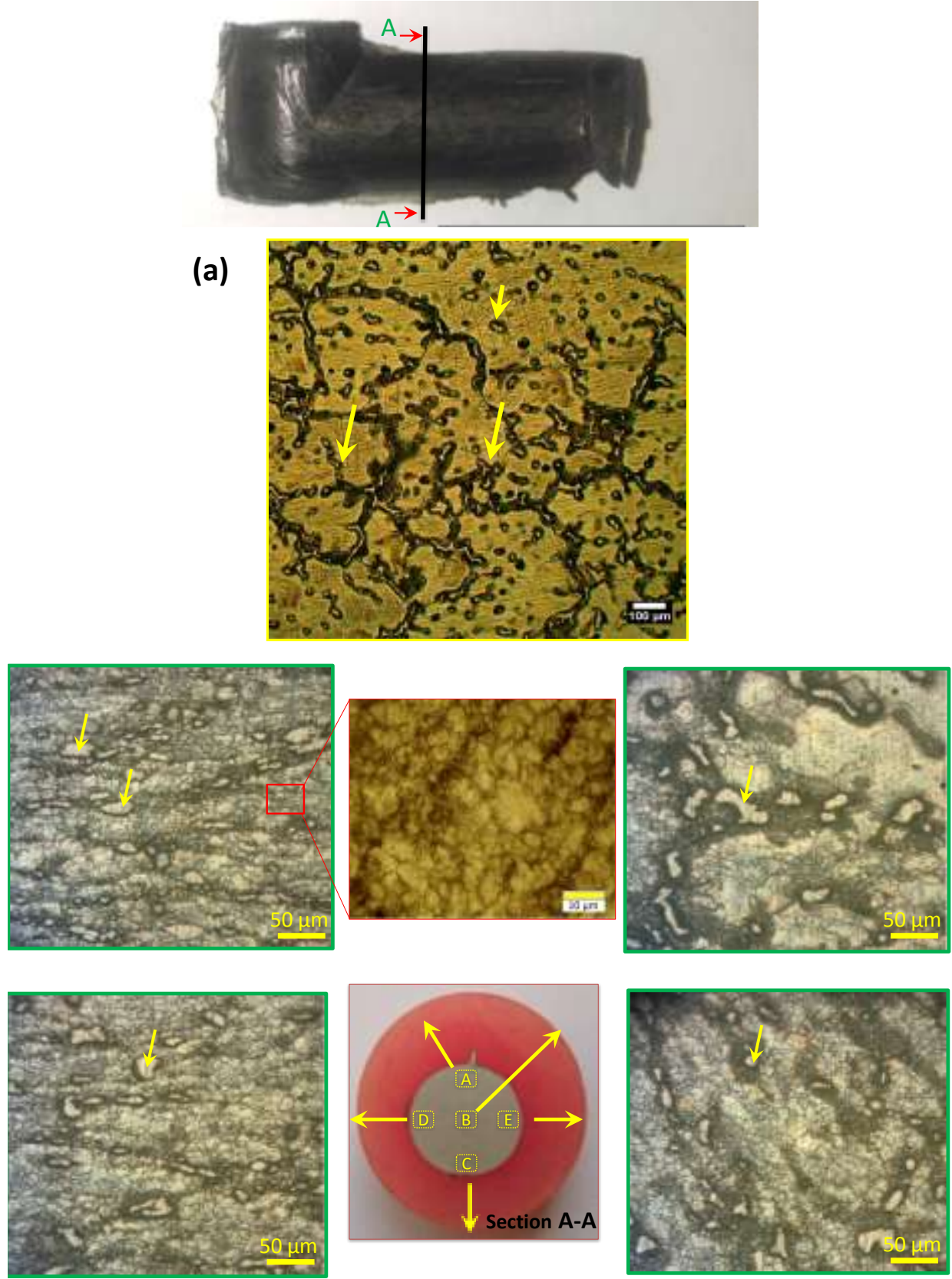

(b)

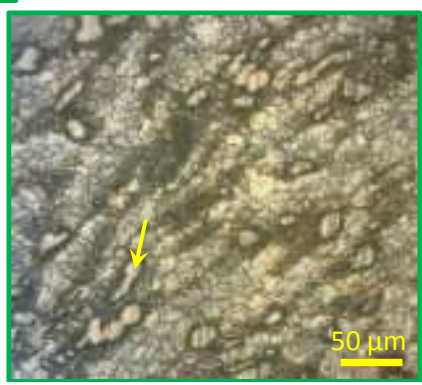

Fig. 2. CECAP processed sample and optical microstructure of (a) unprocessed sample and (b) different zones of CECAP processed samples. 


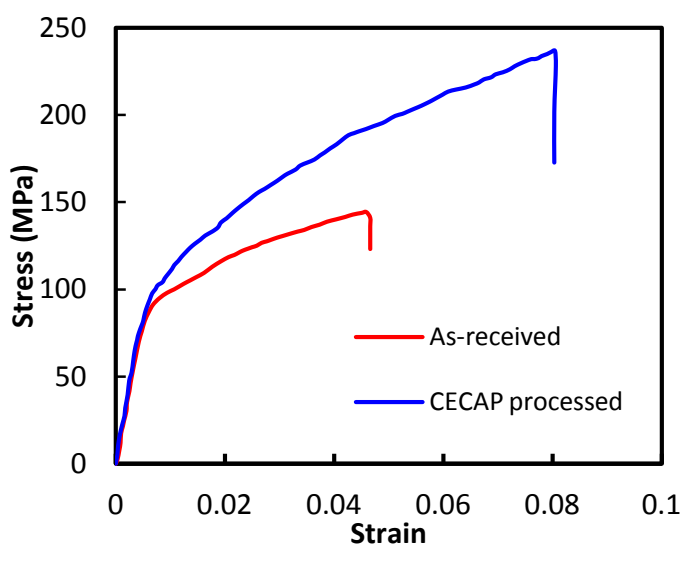

(a)

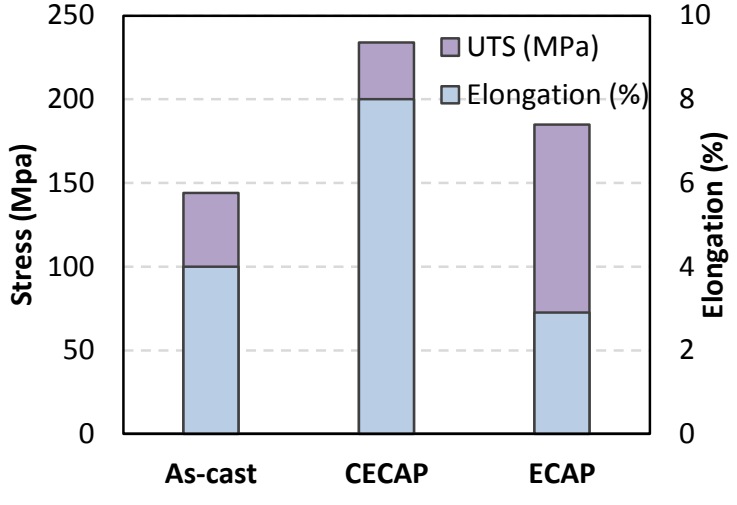

(b)

Fig. 3. (a) True stress versus true strain curves at room temperature for as-received, CECAP processed and ECAP [22] processed samples, and (b) UTS and elongation of samples.

Another reason responsible for better ductility is higher hydrostatic compressive stress [23] in CECAP process compared with ECAP [22, 24]. Fig. 4a-4c illustrate the hydrostatic compressive stress distribution in the ECAP and the CECAP processed samples, respectively. As indicated, hydrostatic compressive stress in CECAP is significantly higher than that in ECAP. Higher hydrostatic pressure causes to limit crack and microvoids initiation and propagation which increases the ductility of the metal $[11,25]$. Therefore, increasing strength and elongation could be attributed to this specific advantage in CECAP process. It was reported that higher hydrostatic pressures lead to improving plasticity of hard to form metals such as magnesium and titanium and might help to activate different slip systems [26, 27]. Also, to compare mechanical properties of as-cast AZ91 after ECAP and CECAP processes, the study of Chung et al. [28], was considered and compared in Fig. 3(b). The results indicate the remarkable advantage of CECAP process over ECAP. As expected, the strength and ductility of one pass CECAP processed sample is higher than ECAP processed sample which is because of the higher hydrostatic pressure and also higher plastic strain.

(a)

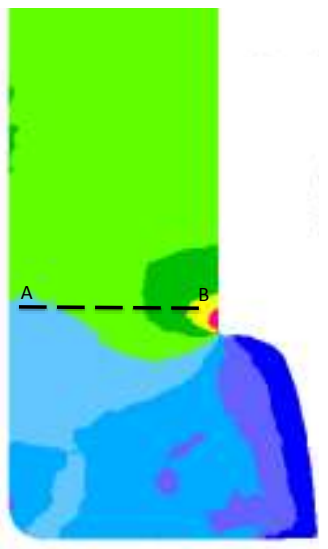

(b)

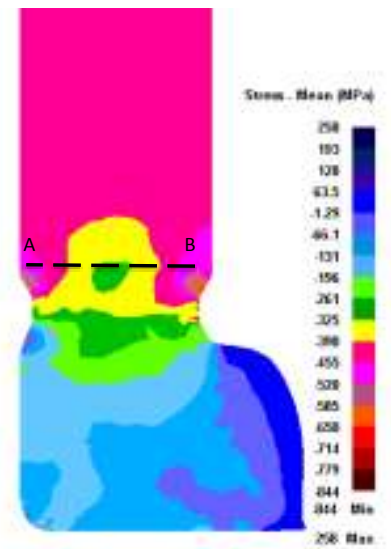

(c)

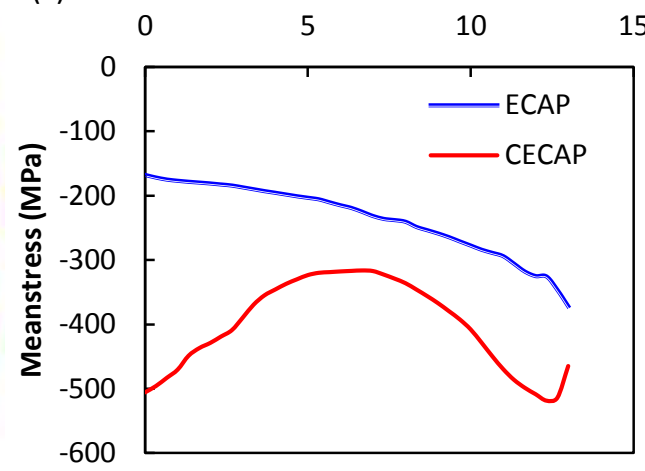

Fig. 4. Mean stress distribution in (a) ECAP and (b) CECAP processes and (c) along A-B path. 
The results of microhardness variation of CECAP processed sample along two defined paths ( $A-B$ and $C-D$ ) compared with unprocessed sample were demonstrated in Fig. 5 (a). Microhardness of the initial sample is about $56 \mathrm{HV}$. Apparently, microhardness was increased significantly after CECAP process consistent with the microstructure refinement and $\beta$ phase precipitation. The hardness of magnesium alloys is highly dependent on grain size due to lack of slip systems [29]. As indicated, there are fluctuations in curves. As mentioned, $\beta$ phase is significantly harder than a $\alpha-\mathrm{Mg}$ phase, and unrecrystalized grains in some regions which were indicated in Fig. 2, could cause fluctuation in the hardness. Fluctuations consistent with grain refinement in A-B path, on the other hand fluctuation do not completely consistent with grain refinement in C-D path. It could be related to distribution of the $\beta$ phase in regions where the hardness was measured. As shown in Fig. 5(b), microhardness value of CECAP processed sample were compared with that of other SPD methods such as compound extrusion (CE) [30], , radial-forward extrusion (RFE) [31], tubular channel angular pressing (TCAP) [32], and acumulative back extrusion [16, 17] at different effective strain levels. It is clear that relatively higher hardness was achieved from CECAP process in comparison with that in others. This exceptional mechanical property may also be related to the high hydrostatic pressure of CECAP process besides high shear strain of ECAP part.

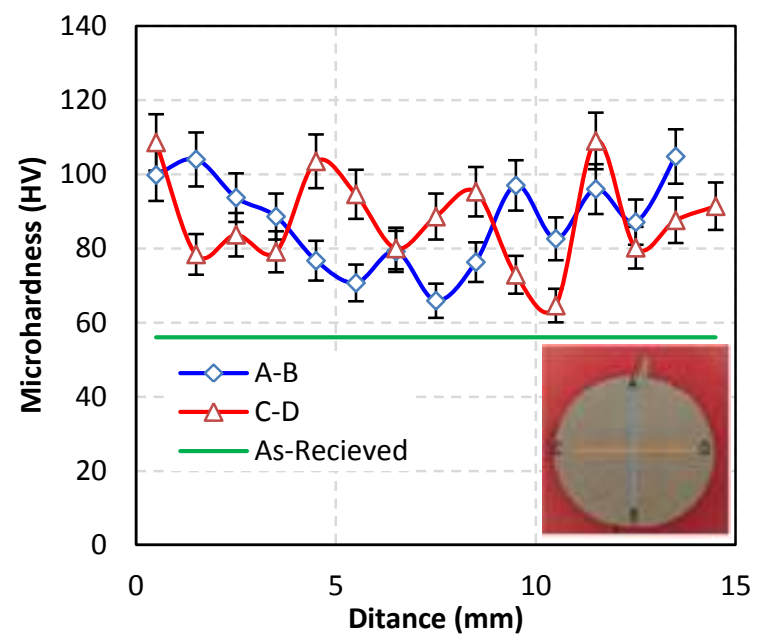

(a)

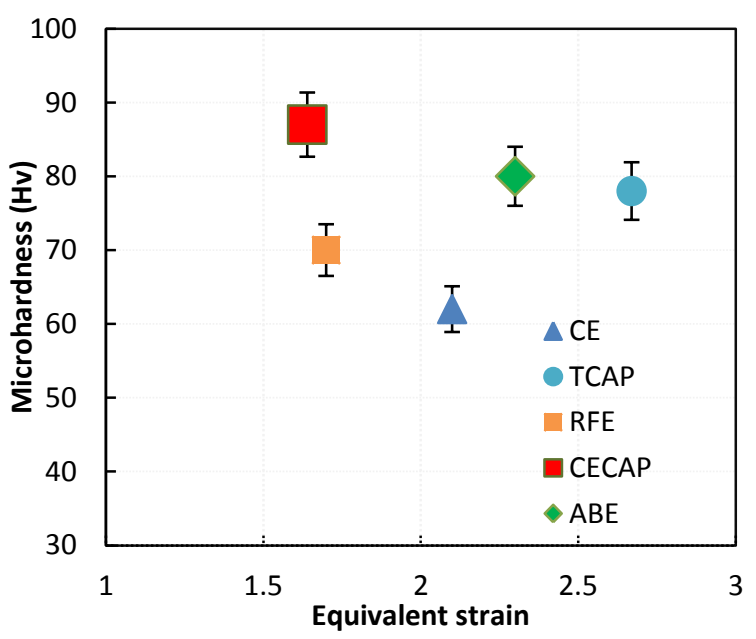

(b)

Fig. 5. (a) Microhardness variation of the initial sample and processed samples along defined paths (b) microhardness of CECAP processed sample in comparison with that of other methods.

\section{Conclusion}

In the current study, CECAP process was proposed and investigated as an efficient SPD approach for producing high strength UFG metals and the following results were obtained:

- This novel technique applied high hydrostatic pressure in comparison with conventional ECAP. 
- Severe grain refinement achieved just after 1pass CECAP process.

- In CECAP process no back pressure is needed in comparison with CEC.

- Ultimate strength increased to $234 \mathrm{MPa}$ after CECAP process from an initial value of $144 \mathrm{MPa}$.

- Ductility was increased from $4 \%$ to $8 \%$ due to influence of high hydrostatic pressure.

- The microhardness was remarkably increased after the CECAP process.

\section{Acknowledgements}

This work was financially supported by Iran National Science Foundation.

\section{References}

[1] R. Valiev, I. Alexandrov, Nanostructured materials 12 (1999) 35-40.

[2] A. Yamashita, Z. Horita, T.G. Langdon, Materials Science and Engineering: A 300 (2001) 142-147.

[3] A. Azushima, R. Kopp, A. Korhonen, D. Yang, F. Micari, G. Lahoti, P. Groche, J. Yanagimoto, N. Tsuji, A. Rosochowski, CIRP Annals-Manufacturing Technology 57 (2008) 716-735.

[4] G. Faraji, A. Babaei, M.M. Mashhadi, K. Abrinia, Materials Letters 77 (2012) 82-85.

[5] R.Z. Valiev, T.G. Langdon, Progress in Materials Science 51 (2006) 881-981.

[6] H. Alihosseini, M.A. Zaeem, K. Dehghani, G. Faraji, Materials Letters 140 (2015) 196-199.

[7] M. Richert, Q. Liu, N. Hansen, Materials Science and Engineering: A 260 (1999) 275-283.

[8] R. Kocich, M. Greger, M. Kursa, I. Szurman, A. Macháčková, Materials Science and Engineering: A 527 (2010) 6386-6392.

[9] G.J. Raab, R.Z. Valiev, T.C. Lowe, Y.T. Zhu, Materials Science and Engineering: A 382 (2004) 30-34.

[10] N. Pardis, B. Talebanpour, R. Ebrahimi, S. Zomorodian, Materials Science and Engineering: A 528 (2011) 7537-7540.

[11] G. Faraji, H. Kim, Materials Science and Technology (2016) 1-19.

[12] Y. Iwahashi, J. Wang, Z. Horita, M. Nemoto, T.G. Langdon, Scripta materialia 35 (1996) 143-146.

[13] M. Richert, H. McQueen, J. Richert, Canadian metallurgical quarterly 37 (1998) 449-457.

[14] K. Huang, R. Logé, Materials \& Design 111 (2016) 548-574.

[15] A. Fata, G. Faraji, M. Mashhadi, H. Abdolvand, Transactions of the Indian Institute of Metals 1-8.

[16] G. Faraji, M. Mashhadi, H. Kim, Materials Science and Engineering: A 528 (2011) 4312-4317.

[17] G. Faraji, M.M. Mashhadi, H.S. Kim, Materials and Manufacturing Processes 27 (2012) 267-272.

[18] A. Chalay-Amoly, A. Zarei-Hanzaki, P. Changizian, S. Fatemi-Varzaneh, M. Maghsoudi, Materials \& Design 47 (2013) 820-827.

[19] S. Xu, S. Kamado, N. Matsumoto, T. Honma, Y. Kojima, Materials Science and Engineering: A 527 (2009) 52-60.

[20] B. Chen, D.-L. Lin, L. Jin, X.-Q. Zeng, C. Lu, Materials Science and Engineering: A 483 (2008) 113116.

[21] K. Meshinchi, Magnesium Alloys-Design, Processing and Properties. InTech (2011).

[22] C.W. Chung, R.G. Ding, Y.L. Chiu, M.A. Hodgson, W. Gao, IOP Conference Series: Materials Science and Engineering 4 (2009) 012012.

[23] G. Raab, E. Soshnikova, R. Valiev, Materials Science and Engineering: A 387 (2004) 674-677.

[24] C.W. Chung, R.G. Ding, Y.L. Chiu, W. Gao, Journal of Physics: Conference Series 241 (2010) 012101.

[25] H. Abdolvand, H. Sohrabi, G. Faraji, F. Yusof, Materials Letters 143 (2015) 167-171.

[26] F. Kang, J.Q. Liu, J.T. Wang, X. Zhao, Scripta Materialia 61 (2009) 844-847.

[27] P. McKenzie, R. Lapovok, Y. Estrin, Acta Materialia 55 (2007) 2985-2993.

[28] C. Chung, R. Ding, Y. Chiu, M. Hodgson, W. Gao, Microstructure and mechanical properties of an as-cast AZ91 magnesium alloy processed by equal channel angular pressing, in: IOP Conference Series: Materials Science and Engineering, vol 4, IOP Publishing, 2009, p. 012012. 
[29] Y. Chino, M. Kobata, H. Iwasaki, M. Mabuchi, Acta materialia 51 (2003) 3309-3318.

[30] Q. Chen, Z. Zhao, D. Shu, Z. Zhao, Materials Science and Engineering: A 528 (2011) 3930-3934.

[31] S. Jamali, G. Faraji, K. Abrinia, Materials Science and Engineering: A 666 (2016) 176-183.

[32] G. Faraji, M.M. Mashhadi, H.S. Kim, Materials Letters 65 (2011) 3009-3012.

\section{Figure captions}

Fig. 1. (a) Schematic of the CECAP process and die parameters, and (b)-(e) different stages of the process.

Fig. 2. CECAP processed sample and optical microstructure of (a) unprocessed sample and (b) different zones of CECAP processed samples.

Fig. 3. (a) True stress versus true strain curves at room temperature for as-received, CECAP processed and ECAP [22] processed samples, and (b) UTS and elongation of samples.

Fig. 4. Mean stress distribution in (a) ECAP and (b) CECAP processes and (c) along A-B path.

Fig. 5. (a) Microhardness variation of the initial sample and processed samples along defined paths (b) microhardness of CECAP processed sample in comparison with that of other methods. 